\title{
Открытость произведения и метафора в постмодернистской архитектуре
}

\author{
А.А.Худин, ННГАСУ, Нижний Новгород
}

Статья содержит результаты исследований, касающихся теории зарубежной архитектуры XX века, претерпевшей радикальные преобразования, произошедшие вследствие смены парадигм. Рассматривается проблематика «открытого произведения» в терминах итальянского философа, специалиста по семиотике У. Эко применительно к архитектуре. Выявляется специфика творческой деятельности архитектора в эпоху постмодерна, когда нормой становится понимание архитектуры как текста, открытого для свободной интерпретации пользователями, к которым он адресуется. Рассматриваются факторы сотворчества с адресатом, динамичности архитектурного текста, адресования текста, множественности кодов, инвариантов прочтения. Отдельно делается акцент на вопросе метафоры как одного из главных инструментов постмодернистского архитектора, как образа мышления в режиме нового эклектизма. Исследование затрагивает проблемы постмодернизма как стиля, открывающего возможность к освобождению от любых форм нормирования, социального программирования, политической обусловленности. В статье представляется направление развития новой герменевтики, предполагающей работу с бесконечной цепью метафор при работе с интертекстом культур, объединённых между собой в условиях открытого общества конца XX - начала XXI века.

Ключевые слова: архитектура, теория архитектуры, постмодернизм, теория стиля, метафора в архитектуре, открытое произведение

The Openness of Work and Metaphor in Postmodern Architecture

A.A.Khudin, NNGASU, Nizhny Novgorod

This article contains the results of research on the theory of foreign architecture of the 20th century in connection with the radical changes in professional thinking that took place because of the change of paradigms. The problematic of the "open work" in terms of the Italian philosopher and semiotics specialist U. Eco is considered in relation to architecture. The article reveals the specificity of the architect's creative activity in the epoch of postmodernity when the understanding of architecture as a text open for free interpretation by the users to whom it is addressed has become the norm. The author considers the factors of cocreativity with the addressee, dynamism of architectural text, text addressing, a plurality of codes, and invariants of reading. The article is also focused on the metaphor as one of the main tools of postmodern architect, as a way of thinking in a new eclecticism mode. The study touches upon the problems of postmodernism as a style opening up the possibility of liberation from any forms of rationing, social programming, and political conditioning. The article presents the direction of the new hermeneutics, which involves working with the endless chain of metaphors while working with the intertext of cultures, united between each other in the open society of the late 20th and early 21st century.

Keywords: architecture, theory of architecture, postmodernism, theory of style, metaphor in architecture, open work.

Постмодернистская архитектура до сих пор остаётся актуальной, но её теоретические основы не изучены полностью и всесторонне. Одно из её основных характерных отличий В том, что она является так называемой «говорящей» архитектурой. Её образы предполагают множественность прочтений, и её произведения определяются как «открытые», что требует отдельного детального рассмотрения.

Экстраполируя теории философа У. Эко (Umberto Eco) на архитектуру, можно говорить о том, что архитектурные «тексты» (произведения) в эпоху постмодерна воспринимаются как открытые, свободные для интерпретаций, существующие в режиме сотворчества с адресатом. Оригинальный смысл архитектурного произведения трактуется как гибкий, изменчивый, трансформируемый. В центре философии «лингвистической» архитектуры становится вопрос коммуникации, при которой система сигнификации (значения) обладает высоким уровнем вариабельности, и изначально при создании архитектурного произведения в него вкладывается соответствующая возможность и определённый потенциал.

Способность к реинтерпретациям закладывается как возможность исторического характера, когда новые значения присваиваются архитектурному произведению по мере смены эпох, так и индивидуального характера, когда каждый зритель имеет право на индивидуальное видение, отличное от тех или иных форм конвенций. Объект интерпретации лишается жёсткости, закрытости, герметичности, его границы растворяются.

Степень открытости для прочтения зависит от того, к кому именно обращено содержание архитектурного произведения. И это, в свою очередь, обозначает проблему адресования. Она существует в условиях невозможности нахождения конкретного, фиксированного адресата, так как текст архитектурного произведения не обладает статичными свойствами, но пре- 
бывает в динамике и множественности воспринимающих его субъектов, которые, в свою очередь, не обладают константностью и унифицированностью.

Как известно, модерн ${ }^{1}$ предполагал обращение к усреднённому адресату, соответствующему установленным нормам современности и находящемуся в усреднённом положении [например, жилые дома нидерландского архитектора Я. Ауда (Jacobus Oud) в Хук-ван-Холланде] (рис. 1), определённом репрессивными механизмами государства (например, посольство Чехословакии в Германии, арх. Владимир Махонин, 1974) (рис. 2). В эпоху постмодерна обращение идёт к дифференцированному множеству, которое не предполагает следования некой норме или стандарту восприятия, однозначному реагированию и следованию единственно верной интерпретации.

Отказ от восприятия текста, как анализируемого в рамках него самого, расширяет схему «0тправитель-СообщениеАдресат», дешифруемую посредством единого консенсусного

${ }^{1}$ Термин «модерн» используется как наименование эпохи соответствующей модернизму, а не как разновидность ар-нуво.

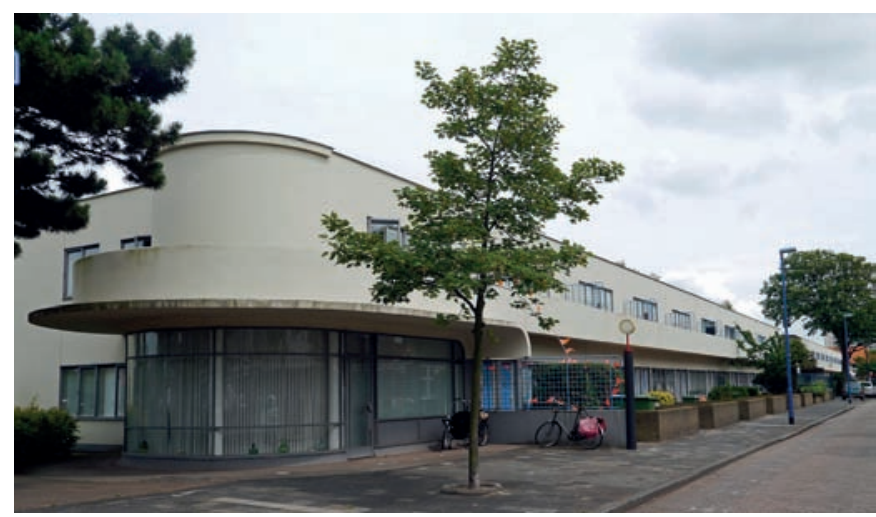

Рис. 1. Жилые дома в Хук-ван-Холланде. Роттердам, Голландия. Архитектор Якоб Ауд. 1927 год. Фото из открытых источников сети Интернет

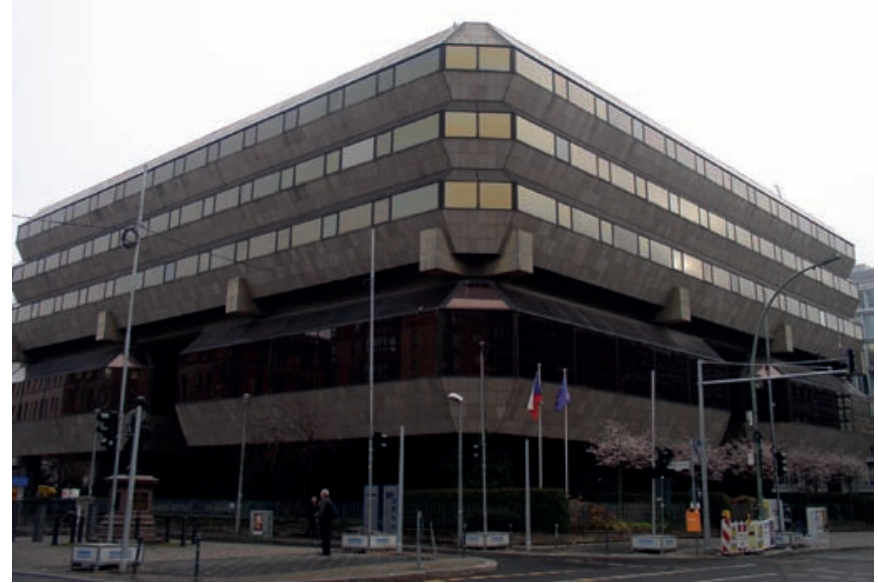

Рис. 2. Посольство Чехословакии. Берлин, Германия. Архитектор Владимир Махонин. 1974 год. Фото из открытых источников сети Интернет кода. Это обеспечивается посредством допущения множественности и разнообразия кодов, которыми пользуются адресаты в зависимости от их культурной, темпоральной, ситуативной принадлежности и идентификации. Адресат получает право на собственные предположения, объяснения, гипотезы в отношении сообщения, не предполагающего более однозначного содержания, но становящегося формой, в которую могут быть внедряемы различные смыслы. Происходит разделение на код автора и коды адресатов, которые могут не совпадать и находиться в самых различных отношениях. При этом наблюдается парадокс, при котором варианты интерпретаций как бы исключают «ошибочность» в отношении исходных смыслов, так как не являются более обязательными и однозначными. Здесь допустимо ввести категорию индетерминированности (необусловленности), допускающую свободное метафорирование и проистекающую из неоднозначности выражения, неоднозначности содержания, неоднозначности интерпретации.

Языковой код и стиль постмодернизма в архитектуре предполагает снижение значимости эксплицитных (явных) отсылок к конкретному адресату, обязательности обладания им равной с автором компетенцией, принадлежности к тем же обстоятельствам. Универсальность языка постмодернизма не заключается в обращении к среднестатистическому человеку эпохи модерна или к фиксированному кругу потребителей. 0 H не обладает жёстким структурированием, ведущим читателя или зрителя от пролога к однозначной развязке по прямой линии, заданной автором. Он не выносит единой моральной оценки, но делает попытку обращения к неопределённому, анонимному, разнообразному множеству, которому предлагается движение по лабиринту с множественностью маршрутов, избираемых адресатом в зависимости от его условий, заданностей, воли и обстоятельств. Это открывает путь к соучастию и партисипации со стороны читателя или зрителя, который получает широкий спектр свобод, не ограничиваемых обязательностью сосуществования в той же реальности, что и автор. Интерпретатор обретает право на соавторство за счёт множественности сосуществующих параллельно и пересечённо реалий постмодернистского общества, не сводимых к единому вектору. Однозначность и монадичность реальности распадается, она вуалируется и прячется под масками альтернатив. Это удаление от сведе́ния мира к «единой» и «неоспоримой» реальности модерна посредством символов, знаков, метафор можно найти ещё у испанского философа Х. Ортега-и-Гасстета (José Ortega y Gasset), который утверждал: «Поистине удивительна в человеке эта мыслительная потребность заменять один предмет другим не столько в целях овладения предметом, сколько из желания скрыть его. Метафора ловко прячет предмет, маскируя его другой вещью; метафора вообще не имела бы смысла, если бы за ней не стоял инстинкт, побуждающий человека избегать всего реального» [1, с. 243].

В контексте вышесказанного уместно рассмотреть варианты взаимодействия читателя архитектурного текста как со- 
автора по целому ряду направлений - прочтений, которые мы попробуем проиллюстрировать на примере анализа здания посольства США в Афинах за авторством В. Гропиуса (рис. 3):

- контекстуальное прочтение: восприятие здания как включённого в определённую среду, имеющую сеть взаимосвязей с другими объектами (специфику архитектуры здания уместно проинтерпретировать как контекстуальную и определить особенности его стилистики, исходя из попытки совершить дипломатический реверанс в адрес культуры страны, в которой представлено посольство);

- ситуативное прочтение: восприятие здания в рамках конкретной временной, культурной, стилистической и прочей обусловленности, его включённости во внешние обстоятельства (стилистику здания посольства допустимо воспринять как выражающую распад позднего модернизма, уступающего свои рационалистические позиции неоисторизму);

- энциклопедическое прочтение: восприятие здания в рамках соответствующей культурной системы, к которой оно принадлежит, подразумевающей компетенции относительно возможных закодированных сообщений (архитектуру здания посольства можно читать как выражение универсальных принципов классицизма, вневременных по своей сути и выражающихся даже в модернистской архитектуре периода его наивысшего расцвета);

- интертекстуальное прочтение: восприятие здания как имеющего отсылки к предшествующим архитектурным произведениям, связанным с данным объектом (здание посольства уместно соотнести с архитектурой Парфенона, которым вдохновлялся автор в ходе проектирования);

- риторическое прочтение: восприятие здания как заключающего в себе метафору или другой троп (здание посольства, эксплуатирующее исторические аллюзии, демонстрирует статус государственного здания как воплощения принципов порядка и закона, выраженныхв классицистических символах);

- идеологическое прочтение: восприятие здания с точки зрения тех или иных ценностных ориентиров и убеждений

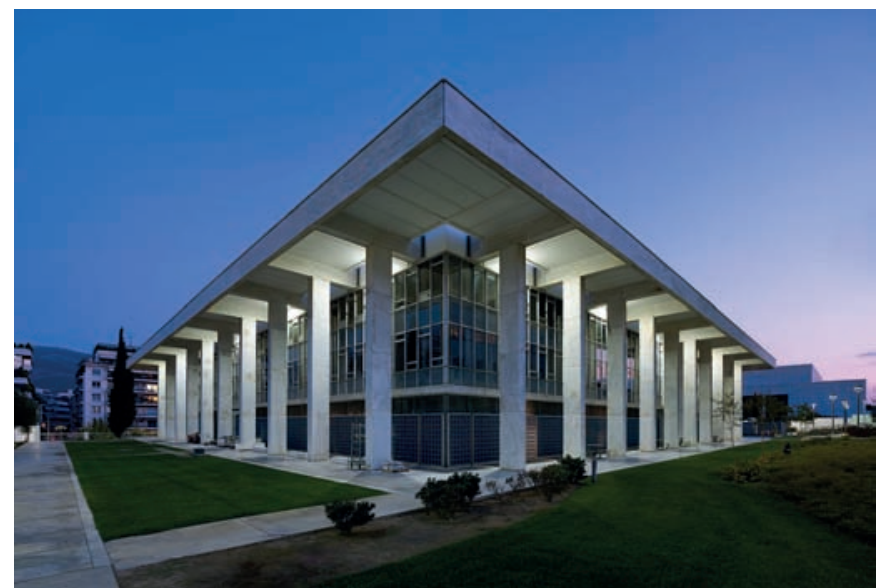

Pис. 3. Посольство США. Афины. Греция. Архитектор Вальтер Гропиус. 1961 год. Фото Йоргиса Еролимбоса (Yiorgis Yerolymbos) (интерпретация здания посольства как воплощающего греческий логос, как символа демократических принципов в приложении к современности);

- селекционное прочтение: восприятие здания с точки зрения выбора определённых его элементов как более значимых, с отсеиванием второстепенных (здание посольства может прочитываться как символ богатства, как демонстрирующее успешность экономического режима (ША);

- абстракционное прочтение: восприятие здания с точки зрения макровысказывания, стоящего за ним (возможность прочтения здания посольства как символа мультикультурализма, характерного для (ША).

Таким образом, мы можем видеть различие между фабулой здания и его сюжетом. Фабула здесь - очевидный синтез модернистских и историзирующих форм. Сюжет же - история, которая повествуется через эту фабулу, но подразумевает целый ряд возможных интерпретаций, что демонстрируют это здание как «открытое произведение», имеющее ряд свобод для «соавторства» читателя, который толкует и дешифрует объект, придавая нарративу различные смыслы. Дизъюнкция в вероятностных интерпретациях возникает в тот самый миг, когда от формы мы переходим к знаку, выраженному через неё, и этот миг - это момент включения адресата в игру.

Потребитель-интерпретатор вынужден совершать выходы за пределы повествования с целью определения его смысла за счёт обращения к внешним связям, как некое «расширение» либо «углубление» в произведение за счёт поиска новых внутренних связей. Причём на проанализированном примере мы видим, что данные интерпретации могут быть множественными, альтернативными, противоречивыми, но не взаимоисключающими по факту бытия в плюралистичном мире эпохи постмодерна. И процесс расшифровки метафоры в данном случае становится скорее актом гносеологическим, нежели чисто эстетическим.

Как формулировал это Х. Ортега-и-Гассет: «0днако эстетика видит в метафоре лишь завораживающий отсвет

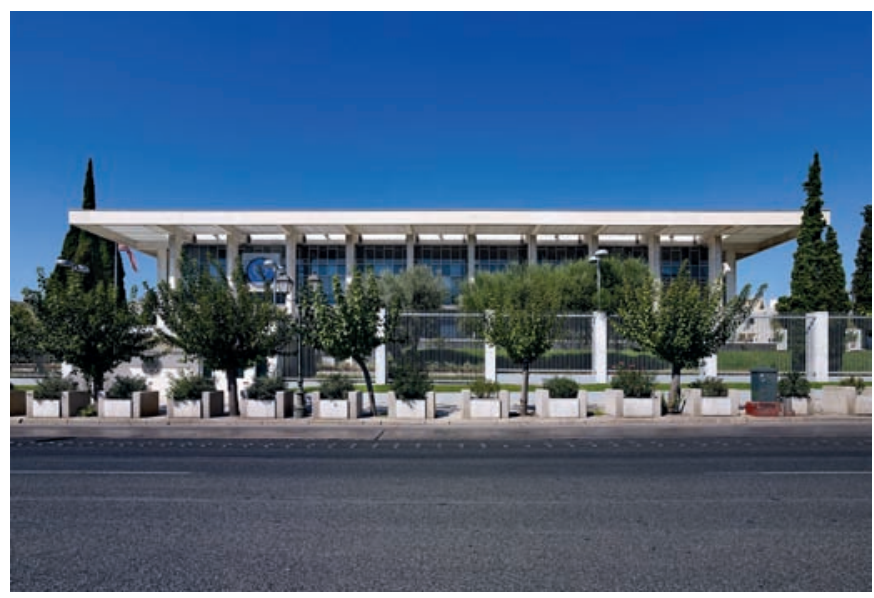


прекрасного. А потому мало кто в должной мере понимает, что метафора - это истина, проникновение в реальность. И, стало быть, поэзия есть, среди прочего, исследование: она вырабатывает столь же положительные знания, как наука» [1, с. 208]. Кажущаяся простота и очевидность исследованного архитектурного артефакта - это «простое и доступное», но если при расшифровке мы двигаемся дальше, то видим «трудное и неуловимое», что не сводится к примитивному оперированию категориями функции и пользы.

Метафора здесь становится инструментом, посредством которого «радиус действия мысли» значительно увеличивается. Её возможно интерпретировать как новый метод и образ мышления, присущий постмодернистской архитектуре, которая не стремится к модернистскому преодолению границ, но к оперированию тем, что лежит вне границ рационального: «Я не хочу сказать, будто благодаря ей [метафоре] преодо-

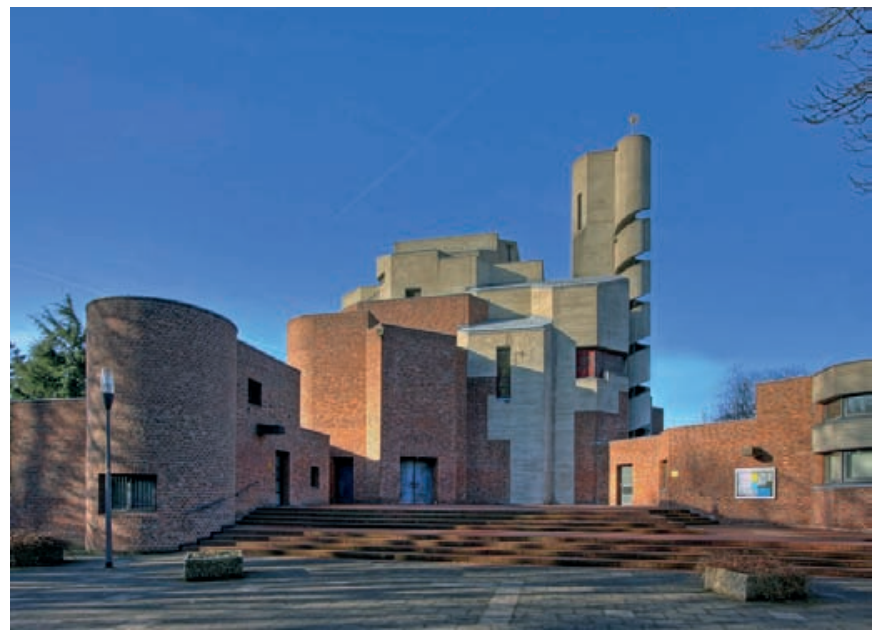

Рис. 4. Католическая церковь. Кёльн, Германия. Архитектор Готфрид Бем. 1968 год. Фото из открытых источников сети Интернет

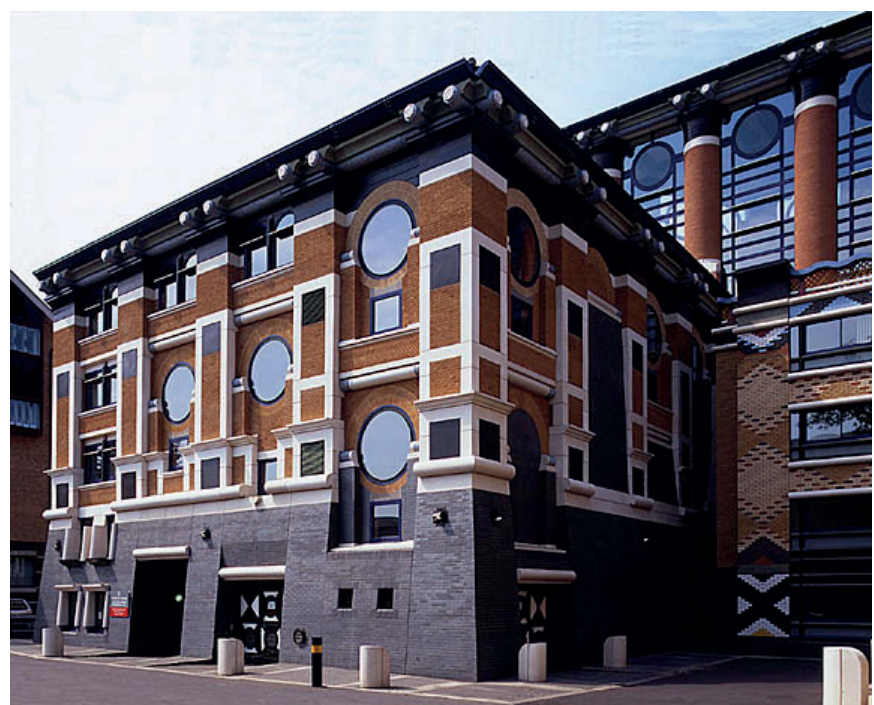

Рис. 5. Бизнес-школа. Кембридж, Англия. Архитектор Джон Аутрам. 1995 год. Фото из открытых источников сети Интернет леваются границы мышления. Она всего лишь обеспечивает практический доступ к тому, что брезжит на пределе достижимого. Без неё на горизонте сознания оставалась бы невозделанная область, в принципе входящая в юрисдикцию разума, но на самом деле безвестная и неприрученная» [1, с. 207].

Адресат, таким образом, имеет право на свободное взаимодействие с текстом произведения в режиме «эклектика». Он выбирает вариант взаимодействия, уровень текста, применение кода для дешифрации, в том числе и по глубоко личным мотивам, имеющим отношение лишь к его собственным психическим и интеллектуальным спецификам, с сохранением права на индивидуальную реальность, неоднозначность расшифровок, интеллигибельных или сенсибельных форм коммуникации с ним. Специфика авторской деятельности при создании «открытых произведений» заключается в наличии ряда свобод в выборе формы, обращении к стилю, избирательности в приёмах, праве на вариации и переосмысления используемых элементов, возможности коллажирования и гибридизации.

Постмодернистский архитектурный объект всегда предполагает импровизации, вольную комбинаторику, возможность работать с широким полем источников, с допуском на их трансформацию в зависимости от концепта. Ему чаще всего присущи черты незавершённости, децентрирования, хаотичности, полифоничности элементов [например, католическая церковь в Кельне(Германия), немецкий архитектор Годфрид Бем (Gottfried Böhm), 1970] (рис. 4). Как писал об этом немецкий философ Т. Адорно (Theodor Adorno): «Загадочное в произведениях искусства состоит в их незавершённости. Если бы в них присутствовала трансцендентность, они были бы мистериями, а не загадками; загадками они являются потому, что, будучи незавершёнными, «недостроенными», они отрицают то, чем хотят, тем не менее, быть сами» [2, с. 186]. Он намекает также на чисто постмодернистский аспект самокритики и подвергания сомнению даже собственных основ.

Идея, лежащая в основе постмодернистского сооружения, обычно предполагает открытость в плане интерпретаций, множественность смыслов, оперирование метафорами и символами [например, бизнес-школа в Кембридже, Англия, британский архитектор Джон Аутрам (John Outram), 1995] (рис. 5). Этим здания обычно дистанцируются от завершённых, целостных, монадичных структур, которые могут восприниматься однозначно. Напротив, такой объект вовлекает зрителя в процесс отреагирования, в ту или иную форму взаимодействия, будучи «говорящим», стимулирующим к ответной со-деятельности, в которой адресат может выражать свои точки зрения, вкусовые пристрастия, позиции. Умберто Эко говорит об этом как о результате бегства от старых, респектабельных преставлений, от необходимости. И эта склонность к нечёткому и неопределённому отражает кризис современной цивилизации...» как «многополярного мира... не обладающего организующим центром, привилегированными точками зрения, в котором все перспективы одинаково правомочны и богаты возможностями» [3, с. 107-108]. 
В этой ситуации для У. Эко главным становится «приглашение к соучастию» как «возможность многочисленных и многообразных личных инициатив» в отношении произведений, которые предлагаются адресату для завершения через личное участие. При ответном реагировании со стороны адресатов архитектурный артефакт получает дополнительные смыслы, расширяя своё значение, и обретает дополнительную ценность в зависимости от роста количества резонансов. Подобную позицию можно встретить у французского теоретика искусства Марселя Дюшана (Marcel Duchamp), который полагал, что творческий акт осуществляется не одним только художником; но зритель помещает художественное произведение в соприкосновение с внешним миром, пытаясь распознать его внутренние качества и интерпретировать его; и таким образом он своим участием обогащает творческий акт. Это прямо противоположно модернистским подходам, при которых артефакт либо «молчит», либо повествует лишь о своей функции, подразумевающей одномерное и единственно правильное использование и только один вариант прочтения. Это точно формулировал русский художникабстракционист В. Кандинский: «Звук молчания, привычно связанного с точкой, столь громок, что он полностью заглушает все прочие её свойства. Все традиционные привычные явления притупляются однообразием своего языка. Мы не слышим больше их голосов и окружены молчанием. Мы смертельно поражены “практически целесообразным"» [4].

Такая линия в искусстве предполагала скованность социальной программой, экономической обусловленностью, идейной направленностью. Постмодерн, снимая долженствование и обязательность заточения художника в эти рамки, дарует культуре открытый свободный символ, в корне отличный от однозначности понимания аллегорий премодерна и единственности смысла образов модерна. Он лишает любой знак авторитарной запрограммированности, ведущей к руководству восприятием зрителя, ориентацией его на одну точку зрения на произведение. Постмодернистский артефакт стремится к намёку, к поиску небуквального смысла, указанию на неисчерпаемые инварианты прочтений, романтическую неопределённость, символическую многозначность. Постмодернизм даёт возможность к диалогу или даже спору в отношении воспринимаемого, охраняется право зрителя на выстраивание собственных оценок, мнений и выводов в отношении объекта архитектуры. Происходит тотальный отказ от бинарного мышления модернизма, ставящего оппозицию между верным и неверным, истинным и ложным. Этот отказ ведёт к бытию в сфере неопределённости. И здесь мы видим основу для отречения от однозначных наименований, к которому склонны постмодернисты. Как говорил об этом швейцарский архитектор Марио Ботта (Mario Botta) в своём интервью в 2015 году: «Когда перед тобой на столе лежит проект, то знать, кто ты - рационалист, пост-традиционалист, модернист или постмодернист, - совсем не обязательно. Я думаю, что все эти ярлыки навешиваются культурной модой, в то время как сегодня, в отличие от эпохи больших исторических движений, нет возможности для жёстких определений. Сегодня настолько всего много и всё так быстро меняется, что сложно найти себе строго заданное место... Я очень хотел бы быть представителем “пост-античности"» [5].

Переход от «ясной и простой» рациональности модернизма происходил в направлении пробуждения эмоций, обращения к чувственному миру адресата, взаимодействия с его психикой в большей степени, чем с разумом, чья ценность и актуальность были оспорены в конце XX века, а ещё в его начале можно найти первые симпатии к альтернативному мышлению. Так, Х. Ортега-и-Гассет писал: «Реальность ускользает, прячась от умственного усилия. Тогда-то перед нами и начинает брезжить вторая, куда более глубокая и насущная роль метафоры в познании. Мы нуждаемся в ней не просто для того, чтобы, найдя имя, довести наши мысли до сведения других, - нет, она нужна нам для нас самих: без неё невозможно мыслить о некоторых особых, трудных для ума предметах. Она не только средство выражения, но и одно из основных орудий познания» [1, с. 206].

Метафоризм в постмодернизме можно наиболее верно интерпретировать как манипуляцию означающими, при которых они соотносятся с новыми означаемыми, что интенсифицируется в условиях создания глобальной системы культур - множественных, но связанных по факту открытости их общества. Необходимость в этом возникает исходя из изобретения новых комбинаторных возможностей, созданных для закрытия тех локусов, которые не были предусмотрены исходными кодами, в чём уместно видеть познавательный акт. Расширение контекста ведёт к присвоению новых содержаний, образованию новых ассоциаций и коммуникативных связей. На это также влияет открытие времени, что расширяет «музей», доступный для ссылок и отношений. Результатом становится Пирсово 2 пространство неограниченного знакообразования, в котором каждый элемент культуры взаимоувязывается и объясняется через множество прочих.

Так любое здание в постмодернистском классицизме порождает бесконечную цепь метафор, ведущих в прошлое, требующих археологического расследования по выявлению порядка передачи значений от символа к символу, ведущих от античности до конца XX века. Все это сопровождается дешифрацией авторского языка, а затем таким же исследованием метонимических цепочек ассоциаций у интерпретирующих произведение адресатов. Этот процесс становится двигателем и стимулятором развития эстетики постмодерна, и У. Эко сравнивает его с «толкованием снов», позволяющим обнаруживать новые актуальные смежности в «бессознательном» и расширять за их счёт актуальный язык «сознания» культуры. Такая позиция прямо противоположна модернистскому демифологизированному рациональному миру, избавленному от символических и метафорических форм мышления.

\footnotetext{
${ }^{2}$ Имеется ввиду американский философ Чарльз Сандерс Пирс.
} 
Здесь также будет уместно вспомнить позицию немецкого философа Ханса-Георга Гадамера (Hans-Georg Gadamer) по данному вопросу: «Символ - это возможность опознания, подобно тому, как в древности гостя узнавали по tessera hospitalis [знак заключённого между двумя лицами союза гостеприимства]. Но что такое узнавание? "Узнать" - не значит увидеть ещё раз. Это не ряд встреч, узнавание - это опознание уже знакомого. В том и заключается процесс человеческого «обживания» (Einhausung) - я пользуюсь в данном случае термином Гегеля, - что каждое узнавание уже отрешено от случайности первого знакомства и возведено в сферу идеального. Это знакомо всем нам. Узнавание всегда сопряжено с более глубоким пониманием, чем это было возможно при первой встрече. Узнавание позволяет вычленить в преходящем устойчивое. Истинная функция символа и символического содержания всех языков искусства заключается в завершении этого процесса. Но ведь это и есть тот вопрос, который нас так занимал: что же мы опознаем, когда встречаемся с искусством (модернизма. - Авт.), чей язык, словарь, синтаксис и стиль так непривычно пусты, с искусством, которое представляется нам таким чуждым и далёким от великих классических традиций нашей культуры? Разве не в том заключается отличительная особенность современности, что она испытывает острую нужду в символах, что весь прогрессизм одержимости техническим, экономическим и социальным усовершенствованием почти лишает нас возможности узнавания?» [6, с. 316].

Всё вышеизложенное развенчивает миф об обскурантизме постмодернизма. Мы видим в метафорах и знаках архитектурных артефактов постмодернизма проявления новой герменевтики, обращённой к психическому, бессознательному человека и культуры. И её недоговорённость, непрозрачность для исследования, затенённость, многослойность, просвечивание сквозь текст предшествующих исторических событий есть не принцип завуалировать реальность, но попытки проникновения за её изнанку, переход от насильственной рационализации к психологичности и исследованию бессознательного.

\section{Лumepamypa}

1. Гассет, Х.О. Эстетика. Философия культуры / Хосе Ортега-и-Гассет. -М. : Искусство, 1991. - 592 с.

2. Адорно, Т. Эстетическая теория / Т. Адорно. -М. : Республика, 2001. - 526 с.

3. Эко, У. Роль читателя. Исследования по семиотике текста / Умберто Эко. - СПб : Симпозиум, 2005. - 502 с.

4. Кандинский, В. Точка и линия на плоскости / В. Кандинский. - СПб : Азбука-классика, 2005. - 240 с.

5. Интерьвью М. Ботта в Мендризио для А. Вяземцевой [Электронные ресурс] // ARCHI.RU. - Режим доступа: https:// archi.ru/world/65629/mario-botta-nelzya-delat-karikatury-naproshloe (дата обращения 18.01.2021).

6. Гадамер, Х-Г. Актуальность прекрасного / Ханс-Георг Гадамер. - М. : Искусство, 1991. - 368 с.

\section{References}

1. GassetKh.0. Estetika. Filosofiya kul'tury [Aesthetics. Philosophy of Culture]. Moscow, Iskusstvo Publ., 1991, 592 p. (In Russ.)

2. Adorno T. Esteticheskaya teoriya [Aesthetic theory]. Moscow, Respublika Publ., 2001, 526 p. (In Russ.)

3. Eko U. Rol' chitatelya. Issledovaniya po semiotike teksta [The role of the reader. Studies in the semiotics of text]. St. Petersburg, Simpozium Publ., 2005, 502 p. (In Russ.)

4. Kandinskii V. Tochka i liniya na ploskosti [Point and line on the plane]. St. Petersburg, Azbuka-klassika Publ., 2005, 240 p. (In Russ.)

5. Inter'v'yu M. Botta v Mendrizio dlya A. Vyazemtsevoi [Interview with M. Bott in Mendrisio for A. Vyazemtseva]. ARCHI.RU. Access mode: https://archi.ru/world/65629/ mario-botta-nelzya-delat-karikatury-na-proshloe (accessed 01/18/2021). (In Russ.)

6. Gadamer, Kh-G. Aktual'nost' prekrasnogo [The Relevance of Beauty]. Moscow, Iskusstvo Publ., 1991, 368 p. (In Russ.)

Худин Алексей Александрович (Нижний Новгород). Кандидат архитектуры, доцент. Доцент кафедры архитектурного проектирования ФГБОУ ВПО «Нижегородский государственный архитектурно-строительный университет» (603950, Нижний Новгород, ул. Ильинская, 65. ННГАСУ). Эл. почта: hoodin-alex@rambler.ru.

Khudin Alexey A. (Nizhny Novgorod). Candidate of architecture, associate professor. Associate Professor of the Department of Architectural Design of the Nizhny Novgorod State University of Architecture and Civil Engineering (603950, Nizhny Novgorod, Ilinskayast., 65. NNGASU). E-mail: hoodin-alex@rambler.ru. 